\title{
Speciation of Heavy Metals in the Homogeneous Sandy Aquifer Affected by Landfill Leachate
}

\author{
Gintarè Slavinskienė ${ }^{*}$ Arūnas Jurevičius
}

Nature Research Centre, Institute of Geology and Geography, Lithuania

Copyright $@ 2016$ by authors, all rights reserved. Authors agree that this article remains permanently open access under the terms of the Creative Commons Attribution License 4.0 International License

\begin{abstract}
The study based on the thermodynamic computer programme PHREEQC presents changes in migration forms of heavy metals in groundwater calculated based on the changing pollution of groundwater under the hydrogeological conditions of a landfill (sandy aquifer). Under neutral medium conditions, as the pollution of shallow groundwater and the content of organic matter decrease, the amounts of heavy metals in ionic form is found to increase considerably. The intensive pollution zone shows the highest percentage of migration forms of carbonates. Furthermore, the formation of organochlorines causes the formation of migration forms of cadmium chloride in the intensive pollution zone. The calculated saturation index values show that crystallization plays the main role in heavy metal attenuation in glaciofluvial alluvial aquifers.
\end{abstract}

Keywords Heavy Metals, Landfill, Sandy Aquifer, Migration Forms, Thermodynamic Modelling

\section{Introduction}

Landfills represent one of the oldest ways of waste disposal in the world. An erroneous understanding of the solution and rock interaction in the pollutant leaching process as well as irresponsible human behaviour have contributed to the fact that the sites of landfills have been chosen in various land depressions or gravel pits, without taking into account environmental standards [3]. Today the protection of groundwater resources against pollution receives special attention and the hazards caused by landfills are one of the most analyzed problems.

In Lithuania, investigation of municipal waste landfills started soon after Lithuania regained its independence in 1990. There are about 800 registered landfills of different size, which are mainly formed without taking into account the environmental standards and have no leachate collection systems. The composition of municipal waste in Lithuania resembles that of other states of the European Union: paper/cardboard $(10 \%)$, glass $(9 \%)$, metals $(4 \%)$, plastic (13\%), biological waste $(25 \%)$ and other $(25 \%)$.
Biodegradable wastes constitute $49 \%$ [22].

The impact of landfills on the environment depends on their geological and hydrogeological conditions, composition of deposits, environmental morphology and technology of the particular landfill site design [8, 16, 24]. The pollution caused by leachate from a landfill depends on the composition of waste, the operation time of the landfill, its design and climatic conditions. The landfill leachate can be characterized as a water-based solution composed of pollutant groups such as: dissolved organic matter, inorganic macro-components, heavy metals (e.g. $\mathrm{Cd}, \mathrm{Cu}, \mathrm{Pb}, \mathrm{Zn}, \mathrm{Ni}$, and $\mathrm{Cr}$ ) as well as oil hydrocarbons [4, 11].

Due to the effects on the environment and human health, special attention is paid to the assessment of heavy metals in the groundwater. During the last decade, much attention has been paid to the analysis of metal associations with colloidal particles and their distribution in the fractions of different size [5, 18]. Heavy metals comprise a group of chemical elements of a rather high density (usually more than $5 \mathrm{~g} / \mathrm{ml}$ ) and their atomic number is higher than 20 [7]. Processes such as alteration of migration forms, formation of other chemical compounds, sorption, desorption and dispersion cause the potential of metals to migrate in the landfill [1]. Heavy metals enter the groundwater as minerals and rocks solve. Their concentration in natural non-polluted groundwater is low and does not exceed environmental permissible standards [11]. The basic source of heavy metals is anthropogenic pollution. Metals in the groundwater of landfill areas are most often found in cases where industrial waste is disposed together with municipal waste [15]. Generally, it can be said that the behaviour of heavy metals during the leaching process is mainly controlled by sorption, crystallization and complexation. These processes take place simultaneously $[10,16]$.

Therefore, the goal of the present study is to assess the attenuation processes of groundwater with regard to heavy metals. Furthermore, the study seeks to determine the regularities in distribution of migration forms of heavy metals in the shallow groundwater of the landfill area composed of homogenous glaciofluvial, alluvial sandy deposits. 


\section{Materials and Methods}

\subsection{Description of the Landfill Site}

The landfill of Smukuciai is located in the southwestern part of Lithuania $\left(55^{\circ} 05^{\prime} 45^{\prime \prime} \mathrm{N}, 22^{\circ} 42^{\prime} 40^{\prime \prime} \mathrm{E}\right)$ and covers the area of $3.5 \mathrm{ha}$; it lies above the permeable beds without a protective screen. Its exploration started in 1958 and was finished in 2009. As in many other Lithuanian landfills, the monitoring of the landfill, with some breaks, began in 1994. The volume of waste in it reaches about $195,000 \mathrm{~m}^{3}$, while the average thickness of the waste bed is about $5 \mathrm{~m}$. Municipal, industrial, medical, agricultural and construction waste was accumulated in the landfill. The leachate that formed during the entire period of its operation time had not been previously collected and treated. There is no real threat from the landfill to surface water and operated groundwater. This is a typical site of concentrated (point) pollution. The site was selected taking into hydrogeological conditions, the amount of hydrochemical data and the level of polluting components.

The monitoring network formed in the landfill consisted of six wells. The depths of well were between 3,5 and 8,0 meters below the groundwater surface. The 8-year hydrochemical and hydrodynamic monitoring data were used in the study.

\subsection{Hydrogeological Conditions}

The landfill under study lies on the site that is open for migration of pollutants due to its hydrogeological conditions. Sandy deposits prevail in the aeration zone that is on average about 2 meters thick (Fig.1). The thickness of the aeration (unsaturated) zone, lithology and filtration character of the deposits cause the vertical percolation rate and time of water recharge as deep as the shallow aquifer $[7,13]$. Under open hydrogeological conditions, the migration time of pollutants is from several days to two years. The sorption of pollutants in the sandy deposits is rather low; therefore, under these hydrogeological conditions they are quickly washed away to the aquifer, thus polluting it. The lithological structure of the shallow aquifer under the landfill studied is homogeneous with smooth water-permeable layers prevailing; therefore, the scheme of the recharge of shallow groundwater and migration of pollutants is simple. Shallow groundwater in the area of the landfill is accumulated in different sand, silt and partly technogeneous deposits (Fig.1). According to the lithology of the water-bearing deposits, the filtration character of shallow aquifer is good and conditions for the spreading of pollutants are favourable. The volume of waste causes the elevation of the groundwater table in well 50671.

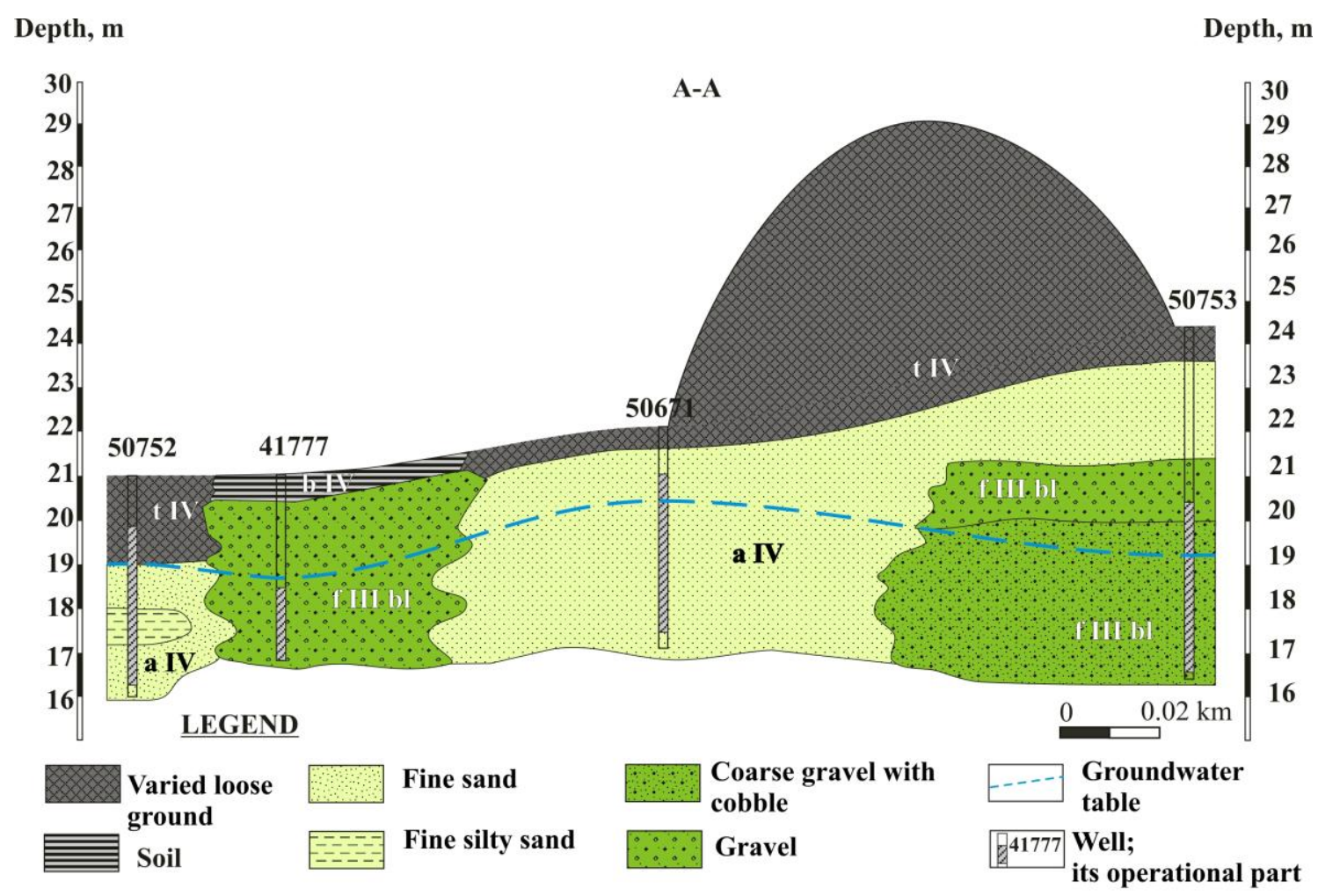

fIIIbl: Fluvioglacial strata Upper Pleistocene of the Baltic Sea

aIV: Strata of Holocene alluvium

tIV: technogeneous deposits

Figure 1. Hydrogeological cross section 


\subsection{Principles Used to Distinguish Pollution Zones}

The main factor in the formation of the chemical composition of groundwater in the area of a landfill is the leachate that is formed as rainwater and other liquids percooling through the waste bed in the landfill [13]. The leachate under gravitation moves towards the water table to flow farther with the groundwater stream. Thus, differently polluted hydrochemical zones are formed in the hydrogeological medium in the direction of groundwater migration, i.e., a spontaneous water-cleaning process takes place. Physicochemical processes such as dilution, ion exchange, precipitation, sorption, redox reaction and degradation control this attenuation process $[8,10,12]$. The effect of these processes depends on factors such as leachate velocity, the degree of saturation of unsaturated zones, organic and inorganic matter in soil, the type of clay, soil fabric and soil stratigraphy [3]. Thus, the change in the chemical composition of polluted groundwater is not a chaotic process. The pollutants form a strictly defined number of geochemical situations expressed by Eh-pH indices. The conditions are formed, which geochemically prevent the entrance of pollutants into groundwater. This buffering capacity can be provided by homogeneous and heterogeneous hydrogeochemical systems [15, 20]. In the present study, the hydrochemical pollution zones were distinguished relying upon a multiannual analysis of chemical components, variations in contents of chemical components during the percolation (recharge) and hydrodynamical parameters, as well as the assessment of the peculiarities of the hydrogeological conditions of the landfill.

\subsection{Determination of Speciation of Heavy Metals}

The contents of heavy metals in polluted groundwater most often are presented as Total Dissolved Metals (TDM). Polluted groundwater, however, contains numerous complex compounds of heavy metals such as colloidal metals, organic and inorganic metal complexes $[2,10,11]$. Determining migration forms of chemical elements enables the assessment of their influence on homogeneous and heterogeneous geochemical processes. Migration forms of heavy metals can be determined using experimental (filtration (screen, ultra) and ion-exchange techniques are used most often) and mathematical modelling methods $[6,9$, 17, 21]. Computer thermodynamical mathematical modelling methods are most popular in the analyses of equilibrium conditions in the polluted hydrogeological medium. They fully reflect the physical geochemical regularities of the processes that take place in hydrogeochemical systems. These computer models are based on solving equilibrium equations for all potential ion pairs in the actual sample (complexation and solubility) and on mass balance equation for all ions in the solution [6]. The third version of the thermodynamical computer programme PHREEQC was used in the study; it is written in the programming language $\mathrm{C}$ that is designed to perform a wide variety of low-temperature aqueous geochemical calculations [1]. This programme has enabled the assessment of the saturation index (SI) and the calculation of the percentage distributions of heavy metal migration forms in different groundwater pollution zones.

\section{Results}

\subsection{The Hydrogeochemical Character of Landfill Environs}

Based on the above-mentioned methods, two point pollution zones were distinguished in groundwater polluted with landfill leachate, i.e. the intensive pollution zone and lower pollution zone (Fig.2). For both zones, a statistical analysis of chemical components was performed, and their average values were applied in thermodynamical computer calculations.

Neutral medium with $\mathrm{pH}$ of 7.09-7.39 was found to prevail in both groundwater pollution zones, where reduction potential ranges from 33 to $295 \mathrm{mV}$ in the intensive pollution zone and from 85 to 399 in the lower pollution zone. This shows better oxidative conditions in the lower pollution zone. High levels of such chemical indices as total dissolved solids (TDS), chlorides and organic matter indicate an indirect effect of landfill leachate on the water quality in the intensive pollution zone.

The intensive pollution zone is notable for its TDS content $\sim 14.6$, chlorides $\sim 124$, and ammonium ion concentrations that are several thousand times higher than those in the lower pollution zone. Intensive oxidation of ammonium and a decrease in dichromate and permanganate COD indices in the lower pollution zone indicate the presence of an oxidative barrier. Thus the two zones are characteristised by different oxidation-reduction medium affecting the influence of physico-chemical processes, variation and formation of migration forms. The intensive pollution zone was found to contain high concentration of organic matter $\left(\mathrm{C}_{\text {org }} 80.2 \mathrm{mg} / \mathrm{l}\right)$ causing favourable conditions for the formation of complex compounds of metals and, in turn, an increase in metal mobility. According to $\mathrm{COD}_{\mathrm{Cr}} / \mathrm{COD}_{\mathrm{Mn}}$ ratio in the intensive pollution zone, the content of poorly degradable organic matter is 2.5 times higher than that of easily degradable organic matter; while this ratio in the lower pollution zone is 4.6. Due to the nitrate reduction in the intensive pollution zone, the organic matter breaks down into carbonic acid and water, thus enhancing the solution of calcareous deposits and causing an increase in calcium and magnesium ions as well as in groundwater hardness. The total hardness of groundwater and the volume of $\mathrm{CO}_{2}$ released during the degradation of organic matter are respectively about 3.5 and 4 times higher in the intensive pollution zone than those in the lower pollution zone. 


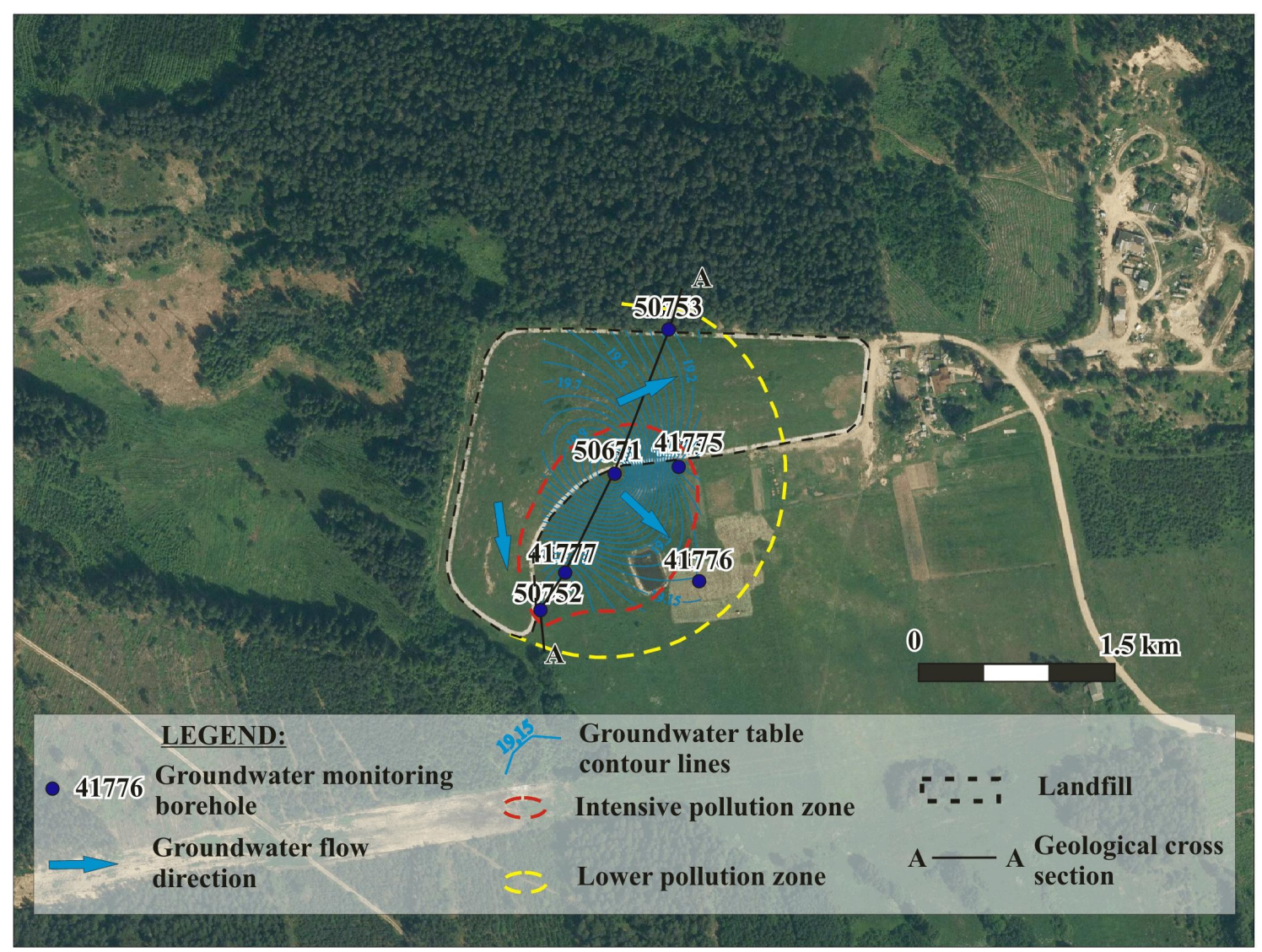

Figure 2. Pollution zones of groundwater in a homogeneous sandy aquifer

\subsection{Variations in Heavy Metal Migration Forms}

Both groundwater pollution zones contain heavy metals, but they do not exceed environmental requirements and are close to the natural background (Tab. 1). The comparison to the studies of other authors shows that the concentrations in the landfill analysed are lower and the differences can be explained by the operation time of the landfill: the leachate from methanogenic landfills usually contains low concentrations of heavy metals $[14,19]$. The difference in heavy metal content in both zones is insignificant, except for nickel and copper (Tab.1).

Table 1. Heavy metal contents $(\mathrm{mg} / \mathrm{l})$ in groundwater

\begin{tabular}{|c|c|c|c|c|c|c|}
\hline & $C r$ & $Z n$ & $C d$ & $N i$ & $P b$ & $C u$ \\
\hline $1^{*}$ & 0,0043 & 0,0424 & 0,0003 & 0,0156 & 0,0042 & 0,0100 \\
\hline $2^{*}$ & 0,0045 & 0,0332 & 0,0003 & 0,0073 & 0,0020 & 0,0064 \\
\hline $3^{*}$ & 0,0030 & 0,0240 & 0,0006 & 0,0020 & 0,0060 & 0,0090 \\
\hline $4^{*}$ & 0,0090 & 0,0240 & 0,0002 & 0,0080 & 0,0030 & 0,0360 \\
\hline $5^{*}$ & 0,0760 & 0,6700 & 0,0680 & 0,1300 & 0,0700 & 0,0700 \\
\hline $6^{*}$ & $0-0,188$ & $0,085-5,31$ & $0,0002-0,0066$ & $0,028-0,084$ & $0-0,016$ & $0,002-0,034$ \\
\hline $7^{*}$ & 0,1 & 1 & 0,006 & 0,1 & 0,075 & 2 \\
\hline
\end{tabular}

Note to table $1: 1^{*}$ - intensive pollution zone; $2^{*}$ - lower pollution zone; $3,4^{*}$ - background of fliuvioglacial, alluvium sediments; $5,6^{*}$ - leachate-polluted groundwater concentration from literature $[6,16] ; 7^{*}$ - maximum permissible levels in less vulnerable areas [23] 
Table 2. Significant migration forms of heavy metals in the groundwater of the intensive pollution zone (row 1) and lower pollution zone (row 2 ) (\% from the total amount of metal)

\begin{tabular}{|c|c|c|c|c|c|}
\hline $\mathrm{Cd}$ & $\mathrm{Cd}^{+2}$ & $\mathrm{CdCl}^{+}$ & $\mathrm{CdCO}_{3}$ & $\mathrm{CdSO}_{4}$ & $\mathrm{CdHCO}_{3}{ }^{+}$ \\
\hline 1 & 53,92 & 29,00 & 9,23 & 4,94 & 1,14 \\
\hline 2 & 95,13 & 0,62 & 1,52 & 2,29 & 0,29 \\
\hline $\mathrm{Cu}$ & $\mathrm{CuCO}_{3}$ & $\mathrm{CuNH}_{3}{ }^{+2}$ & $\mathrm{Cu}(\mathrm{CO} 3)_{2}^{-2}$ & $\mathrm{Cu}^{+2}$ & $\mathrm{CuHCO}_{3}{ }^{+}$ \\
\hline 1 & 77,47 & 9,59 & 9,56 & 1,75 & 1,03 \\
\hline 2 & 76,46 & 0,01 & 0,27 & 18,54 & 1,55 \\
\hline $\mathrm{Ni}$ & $\mathrm{NiHCO}_{3}{ }^{+}$ & $\mathrm{Ni}^{+2}$ & $\mathrm{NiCO}_{3}$ & $\mathrm{NiNH}_{3}{ }^{+2}$ & $\mathrm{NiSO}_{4}$ \\
\hline 1 & 40,94 & 35,76 & 10,02 & 9,31 & 2,95 \\
\hline 2 & 13,49 & 82,74 & 2,16 & 0,003 & 1,81 \\
\hline $\mathrm{Pb}$ & $\mathrm{PbCO}_{3}$ & $\mathrm{PbHCO}_{3}{ }^{+}$ & $\mathrm{Pb}\left(\mathrm{CO}_{3}\right)_{2}^{-2}$ & $\mathrm{~Pb}^{+2}$ & $\mathrm{PbOH}^{+}$ \\
\hline 1 & 65,83 & 20,13 & 8,71 & 2,92 & 0,98 \\
\hline 2 & 47,71 & 22,25 & 0,18 & 22,65 & 5,64 \\
\hline $\mathrm{Zn}$ & $\mathrm{Zn}^{+2}$ & $\mathrm{ZnCO}_{3}$ & $\mathrm{ZnHCO}_{3}{ }^{+}$ & $\mathrm{ZnSO}_{4}$ & $\mathrm{ZnCl}^{+}$ \\
\hline 1 & 54,36 & 23,49 & 15,98 & 4,88 & 0,66 \\
\hline 2 & 90,08 & 3,63 & 3,77 & 2,14 & 0,01 \\
\hline $\mathrm{Cr}$ & $\mathrm{Cr}(\mathrm{OH})_{2}^{+}$ & $\mathrm{Cr}(\mathrm{OH})^{+2}$ & $\mathrm{Cr}(\mathrm{OH})_{3}$ & $\mathrm{CrOHSO}_{4}$ & $\mathrm{CrO}_{2}^{-}$ \\
\hline 1 & 69,12 & 25,68 & 4,50 & 0,47 & 0,06 \\
\hline 2 & 66,19 & 30,68 & 2,83 & 0,16 & 0,02 \\
\hline
\end{tabular}

Changes in the migration forms of heavy metals $\mathrm{Cd}, \mathrm{Cu}$, $\mathrm{Ni}, \mathrm{Pb}, \mathrm{Zn}$, and $\mathrm{Cr}$ due to varying groundwater pollution are presented in Table 2.

Cadmium. As the groundwater pollution increases by $40 \%$, ion forms of cadmium decrease. The levels of carbonate and sulphate forms, however, increase, respectively by $\sim 8$ and $\sim 2 \%$ than those in the lower pollution zone. Cadmium chloride forms constitute a significant percentage in the highly polluted zone because of organochlorine compounds. The chloride forms in the lower pollution zone constitute only $<1 \%$.

Copper. Carbonate forms of copper constitute the largest part in both pollution zones. With the pollution of shallow groundwater increasing, copper makes a significant percentage of its complexes with ammonium. Such complexes in less polluted zone comprise less than $1 \%$. With pollution increasing, there are significantly fewer ionic forms of copper $(\sim 16,7 \%)$. There are more hydroxyl and sulphate compounds in the lower pollution zone, but the differences are small, and the total amounts of migration forms reaches about $0.1-2.6 \%$.

Nickel. Carbonate and ionic migration forms of nickel account for the top percentages in both pollution zones. With the pollution of groundwater increasing, the carbonate forms of nickel increase by $27 \%$, while the ionic nickel forms decrease by $46 \%$. About $9 \%$ of all nickel forms are the complexes with ammonium. There are almost no such complexes in the lower pollution zone. Numbers of sulphate compound forms $(\sim 2 \%)$ remain stable even under varying degrees of pollution of groundwater. Chloride forms of nickel in both zones account for $<1 \%$.

Lead. Carbonate migration forms prevail in both pollution zones, and their percentages remain actually stable. With the pollution of groundwater increasing, the amounts of ionic lead forms decreases by approximately 19\%. The hydroxyl and sulphate complexes of lead are formed in both pollution zones, but their percentage is not significant.

Zinc. The ionic form of zinc prevails in both pollution zones and is found by $35 \%$ more in less polluted water. With the pollution of shallow groundwater increasing, the formation of carbonate compounds increases noticeably. Sulphate and chloride compounds of zinc are detected more often in the intensive pollution zone, but the total amount of these compounds is not significant, i.e. 0.6-5\%.

Chromium. In both pollution zones, chromium occurs mainly in the hydroxyl form and its percentages practically remain stable as the degrees of groundwater pollution change. The ionic forms of chromium reach about $0.05 \%$ in both pollution zones.

\section{Discussion}

The calculations of the migration forms of heavy metals were performed under the thermodynamic equilibrium conditions of inorganic matter. The comparison of the results of the present study to the existing literature shows generally comparable tendencies. First of all, the features of landfills as the focus of research are significant. Specifically, the environs of a landfill, the leaching process, the considerable concentration of chemical compounds and the contents of the leachate cause the changes in migration forms [1]. The present study has revealed that cadmium, zinc and nickel bind to form significant ionic migration forms, while the 
other metals bind with carbonates, chlorides, ammonium and hydroxides to form significant migration forms. Moreover, the results of the study prove that the distribution of metals in various compounds depends on the type of metals, different chemical parameters such as $\mathrm{pH}$, reduction conditions, concentrations of cations and anions, and the amount and type of organic materials. Simple ionic migration forms of simple ions can only be found under weak or strong acid conditions; therefore, ionic migration forms comprise an extremely small part [10,11].

The results of the study show that the concentration of metals is small and does not exceed permissible environmental standards. This is due to the immobile metal complexes found in leachate-polluted groundwater. This is one of the most important aspects that is also reiterated in other studies [4,16,24].

Both the present and other studies indicate that migration forms of heavy metals and the tendencies of their increase or decrease in sandy deposits are similar [10]. The differences can be noted in the sizes of the migration forms of heavy metals as the pollution of groundwater changes. It can be concluded that factors such as the volume of waste, the operation time of the landfill, hydrogeological conditions of the landfill significantly influence not only the dispersion of pollutants, but also the quality of the leachate, heavy metal concentration in groundwater, oxidation-reduction conditions and changes in migration forms of heavy metals. In order to conduct a comparative analysis, the factors influencing the dispersion of pollutants should be the same or at least comparable.

\section{Conclusions}

In neutral medium, with the decrease in the pollution of groundwater and content of organic matter, the ionic forms of heavy metals increase significantly: $\mathrm{Cd}(40 \%) ; \mathrm{Cu}$ (16.7\%); Ni (46\%); Pb (19\%); Zn (35\%). The intensive pollution zone is notable for the top percentages of carbonate forms for nickel, copper and lead. The formation of organochlorine compounds determines the formation of chloride migration forms of cadmium in the intensive pollution zone (29\% from the total amount of the element). About $9 \%$ of all forms of nickel and copper in the intensive pollution zone are soluble and mobile complexes with ammonium. This determines $\sim 2$ times higher concentrations of these metals if compared to those in less polluted groundwater, while the contents of other heavy metals practically do not change under varying degrees of pollution of groundwater in sandy deposits. The effect of geochemical barriers (sulphate and carbonate) is manifested in both pollution zones. As a result, the mobility of metals decreases and crystallisation takes place with precipitation of metals from their carbonate, sulphate and hydroxyl forms. These aspects explain the low contents of heavy metals in the leachate-polluted groundwater of the landfill. Thus, it can be concluded that the influence of metals on the total pollution of groundwater is insignificant.

The sorptive capacity of sandy deposits is low; therefore, it is the crystallisation that plays the main role in the attenuation process of water from heavy metals in glaciofluvial and alluvial aquifers composed of various grained sand deposits.

\section{REFERENCES}

[1] Abu-Rukah, Y, \& Abu-Aljarayesh, I. (2002). Thermodynamic assessment in heavy metal migration at El-Akader landfill site, North Jordan. Waste Management, 22(7), 727-738.

[2] Appelo C.A.J., Postma D. (1993). Geochemistry, Groundwater and Pollution. A.A. Balkema, Rotterdam-Broo kfield, $536 \mathrm{p}$.

[3] Bagchi, A. (1994). Design, construction, and monitoring of landfills. Willey, Canada, $357 \mathrm{p}$.

[4] Barella, C., Bacellar, F., \& Nalini, L. (2013). Influence of the natural oxidation of the leachate organic fraction from a landfill on groundwater quality, Belo Horizonte: Minas Gerais, south-eastern Brazil. Environmental Earth Sciences, 70(5), 2283-2292.

[5] Baumann, T., Fruhstorfer, P., Klein, T., \& Niessner, R. (2006). Colloid and heavy metal transport at landfill sites in direct contact with groundwater. Water Research, 40(14), 2776-2786.

[6] Baun, D. L. (2004). Speciation of Heavy Metals in Landfill Leachate: A Review. Waste Management \& Research, 22(1), $3-23$.

[7] Berkowitz, B. I. Dror, B. Yaron. (2008). Contaminant geochemistry: interactions and transport in the subsurface environment. Springer, Heidelberg.

[8] Bjerg, P., Tuxen, N., Reitzel, L., Albrechtsen, H., \& Kjeldsen, P. (2011). Natural Attenuation Processes in Landfill Leachate Plumes at Three Danish Sites. Ground Water, 49(5), 688-705.

[9] Chidambaram, S., Anandhan, P., Prasanna, M., Ramanathan, V., Srinivasamoorthy, A., \& Senthil Kumar, K. (2012). Hydrogeochemical Modelling for Groundwater in Neyveli Aquifer, Tamil Nadu, India, Using PHREEQC: A Case Study. Natural Resources Research, 21(3), 311-324.

[10] Christensen, J. B, \& Christensen, T. H. (2000). The effect of $\mathrm{pH}$ on the complexation of $\mathrm{Cd}, \mathrm{Ni}$ and $\mathrm{Zn}$ by dissolved organic carbon from leachate-polluted groundwater. Water Research, 34(15), 3743-3754.

[11] Christensen, T. H., Kjeldsen, P., Bjerg, P. L., Jensen, D. L., Christensen, J. B., Baun, A., Anders, A., Hans-J., Heron, G. (2001). Biogeochemistry of landfill leachate plumes. Applied Geochemistry, 16(7-8), 659-718.

[12] Cozzarelli, I., Böhlke, J., Masoner, J., Breit, G., Lorah, M., Tuttle, M., \& Jaeschke, J. (2011). Biogeochemical Evolution of a Landfill Leachate Plume, Norman, Oklahoma.Ground Water, 49(5), 663-687.

[13] Fetter, C.W. (1999). Contaminant hydrogeology, 2nd ed., 
Prentice-Hall, Inc., Englewood Cliffs, NJ., 489 p.

[14] He, P.-J., Xiao, Z., Shao, L.-M., Yu, J.-Y., \& Lee, D.-J. (2006). In situ distributions and characteristics of heavy metals in full-scale landfill layers. Journal of Hazardous Materials, 137(3), 1385-1394.

[15] Karak, T., Bhagat, R., \& Bhattacharyya, P. (2012). Municipal Solid Waste Generation, Composition, and Management: The World Scenario. Critical Reviews in Environmental Science and Technology, 42(15), 1509-1630.

[16] Kjeldsen, P., Barlaz, M. a., Rooker, A. P., Baun, A., Ledin, A., \& Christensen, T. H. (2002). Present and Long-Term Composition of MSW Landfill Leachate: A Review. Critical Reviews in Environmental Science and Technology, 32(4), 297-336.

[17] Kübeck, C., Hansen, C., König, C., Denzig, D., \& Van Berk, W. (2012). Model-based quality management of groundwater resources - catchment area Liedern, Germany. Water Science and Technology: A Journal of the International Association on Water Pollution Research, 66(1), 210-6.

[18] Li, R., Yue, D., Liu, J., \& Nie, Y. (2009). Size fractionation of organic matter and heavy metals in raw and treated leachate. Waste Management (New York, N.Y.), 29(9), 2527-2533.

[19] Lou, Z., Dong, B., Chai, X., Song, Y., Zhao, Y., \& Zhu, N. (2009). Characterization of refuse landfill leachates of three different stages in landfill stabilization process. Journal of
Environmental Sciences, 21(9), 1309-1314.

[20] Milosevic, N., Qiu, S., Elsner, M., Einsiedl, F., Maier, M.P., Bensch, H.K.V., .Bjerg, P.L. (2013). Combined isotope and enantiomer analysis to assess the fate of phenoxy acids in a heterogeneous geologic setting at an old landfill. Water Research 47(2), 637-649.

[21] Obiri-Nyarko, Kwiatkowska-Malina, Malina, \& Kasela. (2015). Geochemical modelling for predicting the long-term performance of zeolite-PRB to treat lead contaminated groundwater. Journal of Contaminant Hydrology, 177-178, 76-84.

[22] Pires, A., Martinho, G., \& Chang, Ni-Bin. (2010). Solid waste management in European countries: A review of systems analysis techniques. Journal of Environmental Management, 92(4), 1033-1050.

[23] The order of the Minister of Environment of the Republic of Lithuania "On approval of environmental requirements to the management of chemically-polluted areas" (issued on 30 April, 2008, No. D1-230)

[24] Zhang, J., Yang, Q., \& Liu, D. (2015). A comprehensive study on numerical analysis of contaminant migration process in compacted clay liner and underlying aquifer for MSW landfill. European Journal of Environmental and Civil Engineering, 19(8), 950-975. 